\title{
The Efficacy of Tiapride and Carbamazepine Combination Therapy in Reducing Alcohol Withdrawal Symptoms: A Systematic Review and Meta-Analysis
}

Authors

Sahar Latifi' ${ }^{1}$ Thomas Messer²

\section{Affiliations \\ 1 Resident of Psychiatry and Psychotherapy, Danuvius Klinik GmbH, Pfaffenhofen an der IIm, Technischen Universität München, Bavaria, Germany \\ 2 Head of Department, Professor of Psychiatry and Psycho- therapy, Danuvius Klinik GmbH, Pfaffenhofen an der Ilm, Technischen Universität München, Bavaria, Germany}

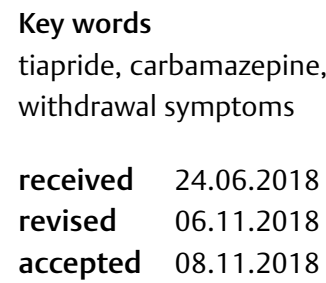

\section{Bibliography}

DOI https://doi.org/10.1055/a-0795-3689

Published online: 6.12.2018

Pharmacopsychiatry 2019; 52: 209-216

(c) Georg Thieme Verlag KG Stuttgart - New York

ISSN 0176-3679

Correspondence

Sahar Latifi, MD

Danuvius Klinik GmbH

Technischen Universität München

Krankenhausstraße 68

85276 Pfaffenhofen an der Ilm, Bavaria

Germany

sahar.latifi@danuviusklinik.de

\begin{abstract}
The combination of tiapride (TIA) and carbamazepine (CBZ) as an alternative treatment option to benzodiazepines and clomethiazole has been investigated by several investigations. We performed a systematic review and meta-analysis to further explore the efficacy of this combination in order to render more definite answers whether this combination can be recommendable in the clinical practice. We systematically searched electronic databases including PubMed (MEDLINE), EMBASE, OVID, Cochrane, Google Scholar, and Scopus for human studies. Statistical homogeneity was checked by $X^{2}$ test and $I^{2}$ using Cochran heterogeneity statistic. Our analysis showed a significant efficacy of the combination of TIA and CBZ in reducing alcohol withdrawal syndrome (AWS) ( $p<0.0001$, $z$-value: 4.07). The cumulative analysis illustrated that the favorable efficacy of this combination therapy has been consistent over time. Our study shows that the combination of TIA/CBZ is an effective treatment in management of AWS in patients with alcohol abstinence. However, the safety of this combination could not be proven, so we recommend its prescription after an informed consent.
\end{abstract}

\section{Introduction}

Alcohol withdrawal syndrome (AWS) can cause a life-threatening condition that increases the concerns for the necessity of suitable and rapid treatments. It has been shown that chronic alcohol consumption induces neuroadaptive changes that involve mainly the gamma-aminobutyric acid (GABA) receptors central noradrenaline, dopamine, and glutamate receptors [1,2]. Studies have shown that a reduced neurotransmission in $\mathrm{GABA}_{A}$ and an enhanced neurotransmission in glutamatergic pathways results in an imbalance between inhibitory and excitatory neurotransmitters [3], which leads to the nervous system hyperactivity [4]. In fact, GABA has an inhibitory effect that suppresses neural activity and thereby it plays an important role in developing the tolerance and inducing the withdrawal syndrome in patients with long-term exposure to alcohol [5]. Recent studies have also shown that a genetic variation in $\mathrm{GABA}_{A}$ receptor subunits affects the risk for developing alcoholism [6]. Furthermore, an increased level of dopamine has been reported in patients with AWS [7]. The involvement of other neuromodulators, such as serotonin and corticotropin-releasing factor, has also been described, which presents the AWS as a complex phe- 
nomenon affecting multiple nerve systems [8]. Triggering this complex matrix of receptors and neurotransmitters to reduce the withdrawal symptoms has been a challenging theme in the recent researches. In this field, many combinations of medications have been studied. The most common treatment options are clomethiazole and benzodiazepines. Bonnet et al. [9] compared the efficacy of clomethiazole and clonazepam in a prospective observational study that revealed no significant difference between these 2 medications. A new study by Sychla et al. [10] showed that both diazepam and clomethiazole were equally effective and safe; however, clomethiazole showed a faster effect, so patients treated with clomethiazole were treated significantly shorter. Furthermore, benzodiazepines have become worldwide the first choice of treatment of AWS because clomethiazole-induced respiratory insufficiency has limited its use in clinical practice [11]. A new study in Germany by Verthein et al. [12] showed that oxazepam is as effective as clomethiazole in treatment of AWS. Although benzodiazepines are prescribed vastly in management of AWS [13], many side effects such as memory deficits and interactions with other drugs have been reported frequently $[14,15]$. The benzodiazepine-induced additive sedation in combination with alcohol can cause respiratory suppression [16]. Furthermore, benzodiazepines can cause additional addiction problems that also should be taken into consideration [17]. Although some beneficial effects of long-term prescription of benzodiazepines in patients with alcohol dependence have been reported [18], they must be prescribed cautiously in clinical practice. Leggio et al. [19] reported that the addictive properties of benzodiazepines increase the focus on non-benzodiazepine GABAergic medications such as carbamazepine (CBZ), which shows promising effects in clinical studies.

CBZ is an anticonvulsive that is typically used for the treatment of seizure disorders and neuropathic pain. However, it has been shown to be effective, safe, and well-tolerable in treatment of AWS [20-22]. Prince and Turpin [23] reported the beneficial effect of CBZ in patients with alcohol dependence, but adverse effects (for example, dizziness, drowsiness, nausea, and vomiting as the most frequent side effects) and drug interactions may limit its usefulness. CBZ is a potent inducer of hepatic cytochrome CYP3A4 and is also known to be an inducer of CYP1A2, 2B6, and 2C9/19, so it may reduce plasma concentrations of medications mainly metabolized by these cytochromes (for example aripiprazole and tacrolimus) through accelerating their metabolism.

Tiapride (TIA) is a dopamine D2 and D3 receptor antagonist. It is used to treat a variety of disorders including dyskinesia, negative symptoms of psychosis, and agitation and aggression in the elderly [24]. A combination of CBZ and TIA has been shown to effectively reduce the withdrawal symptoms without inducing an additive sedation [25]. Since dopamine hyperactivity has been linked with AWS, TIA's antidopaminergic effects can influence withdrawal symptoms favorably. In this combination therapy, TIA works as an anxiolytic whereas the hallucinations, delirium tremens and epileptic attacks by alcohol withdrawal will be targeted by CBZ. In fact, the therapeutic rational is the combined effect on both seizure risk and psychovegetative symptoms without a significant risk for an abuse. This combination has also been shown to be safe even in outpatient settings [26, 27]. However, lack of definite proofs and meta-analysis above all leads to uncertainties in clinical practices. The aim of this study was to review the literature addressing the efficacy and safety of the combination therapy with CBZ and TIA in treatment of AWS. We also performed a meta-analysis to examine the results of the relevant studies in order to render more definite answers if this combination in the clinical practice is recommendable. To our knowledge, this is the first meta-analysis addressing the efficacy of this combination therapy in patients with alcohol dependence.

\section{Methods}

\section{Study design and data collection}

This study is a systematic review that summarizes the findings of previous researches addressing the efficacy and safety of CBZ and TIA in treatment of alcohol withdrawal symptoms. We also performed a meta-analysis to compare the outcomes of relevant literature. We systematically searched electronic databases including PubMed (MEDLINE), EMBASE, OVID, Cochrane, Google Scholar, and Scopus for human studies with the following keywords: "triapride" AND/OR "carbamazepin" AND "alcohol withdrawal" OR "alcohol dependence" OR "alcohol abuse." The references of the retrieved articles were also scanned to detect the relevant literature. All potential published studies up to May 2018 have been reviewed.

\section{Study eligibility criteria}

The relevant studies evaluating the effect of the combination therapy with TIA and CBZ have been considered as eligible. The inclusion criteria were studies on human subjects, existence of adequate comparative data, and application of standard instruments for assessment of withdrawal symptoms for proper comparison. Primary search of databases with mentioned keywords revealed 290 articles, whereby after exclusion the irrelevant article after initial screening, 7 studies could be selected. The main reasons for exclusion were irrelevance of basic theme, lack of adequate comparative data, lack of application a standard method for assessment the AWS, lack of use of a combination therapy of TIA and CBZ (application of monotherapy), and use of other anticonvulsants in combination with TIA. Among the selected articles, 2 studies were case reports (on only 1 single case), so these studies have been also excluded because of lack of the comparative data.

\section{Assessment of alcohol withdrawal symptoms}

Most of the involved studies have used the Clinical Institute Withdrawal Assessment for Alcohol (CIWA) for the evaluation of AWS. CIWA or CIWA-Ar (revised version), is a 10-item scale that is used to assess the severity of alcohol withdrawal symptoms. This instrument assesses the 10 common symptoms of alcohol withdrawal (nausea and vomiting, tremor, paroxysmal sweats, anxiety, agitation, tactile disturbances, auditory disturbances, visual disturbances, headache and orientation) $[28,29]$. Each item on the scale is scored independently, and the summation of the scores correlates to the severity of alcohol withdrawal symptoms. A mild alcohol withdrawal is defined with a score of $\leq 15$, moderate with scores of 16-20, and severe with any score $>20$. All items are scored from $0-7$, except for the orientation category, which is scored from $0-4$. The maximum score is 67 . 


\section{Statistical analysis}

All the statistical analysis was performed using Comprehensive Meta-Analysis version 2 (Biostat, Englewood, NJ, USA). Statistical homogeneity was checked by $\mathrm{X}^{2}$ test and $\mathrm{I}^{2}$ using Cochran heterogeneity statistic, in which $\mathrm{I}^{2}$ higher than $75 \%$ represents a heterogenic data. By heterogeneity the random effect model has been used to calculate the weighted mean difference and $95 \%$ confidence interval $(\mathrm{Cl})[30,31]$. Random effects model enables a proper comparison of data between different studies with little homogeneity with the assumption that the effects being estimated in the different studies are not identical but follow some similar distributions, which makes the synthesis of the information possible. Simulations have shown that this model can provide valid results even under extreme distributional assumptions [32]. This model can also be used in assessment of risk factors in meta-analysis setting [33]. By studies in which no control or comparison groups have been assigned, we used the pre-post model with entering the data of means and standard deviations at the beginning and end of the study. The Rosenthal conservative estimate of 0.7 was used as the pre-post correlation [34]. We have also performed a sensitivity analysis (leave-one-out analysis) to make sure that the results were not influenced by a single study. Leave-one-out meta-analysis involves performing a meta-analysis on each subset of the studies obtained by removing 1 study at a time.

\section{Results}

We summarized the major findings of relevant studies assessing the effect or safety of the treatment with TIA and CBZ in patients going through an alcohol detoxification program in $>$ Table 1 . The combination of TIA/CBZ has been administered in seven studies, in which 6 of them have reported this combination as a safe and effective treatment option. One study evaluated the efficacy and safety of the combination of oxcarbazepine (OXC) and TIA in treatment of AWS, which showed a good efficacy and tolerability in comparison with clomethiazole. Three of the seven studies that tested the combination treatment of TIA/CBZ were open clinical studies without assignment of a control group, so we used the pre-post model in a single group for a proper comparison with other studies. Two studies were case reports that reported a single case, so they could not be entered into the meta-analysis because of different study settings. In 4 studies the severity of the withdrawal symptoms was assessed using the CIWA-Ar scale. This instrument has been widely used for assessment of AWS [44-46]. In only one study the visual analog scale and the Symptom Checklist-90-Revised have been used to assess AWS. However, the assignment of a control group (comparison with clomethiazole and diazepam groups) led to proper assessment of difference between groups, so the evaluation of mean difference and $\mathrm{F}$ change enabled us to enter this study in our meta-analysis, too. At the end, 5 studies were included in our analysis. - Table 2 shows the design and the major outcomes of the included literature.

- Table 3 shows the analysis of heterogeneity with assessment of $\mathrm{I}^{2}$ along with measurement of tau-squared. Since $\mathrm{I}^{2}$ was more than $75 \%(91.7 \%)$, we used the random effect model to enable a proper integration of study results.
Our meta-analysis, which is shown in -Fig. 1, illustrates that the combination of TIA and CBZ could effectively reduce the AWS assessed by CIWA-A. The efficacy of this combination in treatment of withdrawal symptoms was significant $(p<0.0001, z$-value: 4.07$)$. The cumulative analysis shown in $>$ Fig. 2 illustrate that the favorable efficacy of this combination therapy has been consistent over time. Moreover, as a part of sensitivity analysis, we performed a leave-oneout sensitivity analysis by removing 1 study at a time to confirm that our findings were not driven by any single study ( $\triangleright$ Fig. 3 ).

\section{Discussion}

\section{TIA and alcohol dependence}

The favorable effect of TIA in promoting abstinence in patients with alcohol dependency has been reported previously [47]. However, further studies in this field reported contradictory results about the effectiveness of TIA in maintaining alcohol abstinence [48]. Since the dopaminergic hyperactivity has been shown to be related to withdrawal symptoms, the antidopaminergic effect of TIA has been a theme for further investigations assessing the role of this medication in reducing the severity of withdrawal symptoms. TIA demonstrates antidyskinetic and anxiolytic activities [49]. It has also a low potential for interaction with ethanol and low risk of abuse [49]. In this field, Murphy et al. compared the efficacy of a monotherapy with TIA with clomethiazole in patients with alcohol dependence and reported that TIA was more successful in alleviating gastrointestinal and psychological distress but was less effective in preventing hallucinosis [50]. Moreover, studies have shown unsatisfactory results in treating delirium tremens with a monotherapy with TIA [51]. Therefore, its administration in acute alcohol withdrawal should be accompanied by adjunct therapy for hallucinosis and seizures [49]. Not only TIA does not induce the over sedation, but it also does not reduce the memory function, which has been frequently reported by benzodiazepines [52]. TIA selective D2 and D3 dopamine receptor antagonist, whereby its receptor occupancy does not exceed $80 \%$ even at high doses [53]. This explains the reasons why TIA causes rarely side effects such as extrapyramidal symptoms or tardive dyskinesia. This advantage of TIA has been discussed in elderly patients by whom TIA can be used to treat agitation [54] and can improve the clinical symptoms in senile dementia more effectively than risperidone and with fewer adverse effects [55]. The safety of TIA administration is advantageous especially in outpatient setting $[26,27]$. Since TIA provides a safe and efficient treatment option, with a good patient compliance and the little risks for abuse, it can be considered to be administered especially in outpatient setting by mild to moderate AWS. Furthermore, it is to mention, that the required dosage in outpatient setting may be lower compared to the dosage given to inpatient withdrawal. In this regard, Franz et al. [35] treated the admitted patients with $300 \mathrm{mg}$ TIA every $4 \mathrm{~h}$ up to the maximum daily dosage of $1200 \mathrm{mg}$. Soyka et al. [26, 27] performed 2 studies in outpatient setting and administered a daily dosage of $300 \mathrm{mg}$ TIA, which shows a lower required dosage in patients with mild to moderate AWS. Lucht et al. [36] treated the admitted patients with a minimum daily TIA dosage of $600 \mathrm{mg}$ and a maximum of $1500 \mathrm{mg}$, which has been 
- Table 1 The major findings of relevant studies assessing the effect or safety of the treatment with TIA, CBZ, or OXC in patients with alcohol dependency.

\begin{tabular}{|c|c|c|c|c|}
\hline Study & $\begin{array}{l}\text { Year of } \\
\text { publication }\end{array}$ & Setting/design & Methodology & Major findings \\
\hline Franz et al. [35] & 2001 & Pilot study & $\begin{array}{l}\text { Comparison of combination of } \\
\text { TIA and CBZ vs. CLO }\end{array}$ & $\begin{array}{l}\text { The combination of TIA/CBZ was a safe alternative in } \\
\text { alcohol detoxification. Vegetative recovery seemed to be } \\
\text { faster with } T I A+C B Z \text {. }\end{array}$ \\
\hline Lucht et al. [36] & 2003 & $\begin{array}{l}\text { Controlled } \\
\text { open-label } \\
\text { study }\end{array}$ & $\begin{array}{l}\text { Treatment with TIA/CBZ, CLO and } \\
\text { DZP in intoxicated vs. non-intoxi- } \\
\text { cated patients }\end{array}$ & $\begin{array}{l}\text { In non-intoxicated patients, the combination of TIA/CBZ } \\
\text { was as effective and safe as the other groups. In intoxicated } \\
\text { patients, TIA/CBZ was safe but a lack of efficacy has been } \\
\text { detected in } 18 \% \text { of participants. }\end{array}$ \\
\hline Martinotti et al. [37] & 2010 & $\begin{array}{l}\text { Randomized, } \\
\text { single- } \\
\text { blind clinical trial }\end{array}$ & $\begin{array}{l}\text { Comparison of LZP with } \\
\text { pregabalin and TIA }\end{array}$ & $\begin{array}{l}\text { All used medications were safe. The efficacy of pregabalin } \\
\text { was superior to that of TIA and LZP. }\end{array}$ \\
\hline Soyka et al. [26] & 2002 & $\begin{array}{l}\text { Open clinical } \\
\text { study }\end{array}$ & $\begin{array}{l}\text { Combination of CBZ/TIA in } \\
\text { outpatient alcohol detoxification }\end{array}$ & $\begin{array}{l}\text { CBZ/TIA combination is an effective and safe treatment for } \\
\text { outpatient alcohol detoxification }\end{array}$ \\
\hline Soyka et al. [27] & 2006 & $\begin{array}{l}\text { Open } \\
\text { prospective } \\
\text { study }\end{array}$ & $\begin{array}{l}\text { Combination of CBZ/TIA in } \\
\text { outpatient alcohol detoxification }\end{array}$ & $\begin{array}{l}\text { Additional evidence that a combination of CBZ/TIA is safe } \\
\text { and effective by moderate severity of withdrawal symptoms } \\
\text { in an outpatient setting. }\end{array}$ \\
\hline Soyka et al. [24] & 2006 & $\begin{array}{l}\text { Pooled analysis } \\
\text { (retrospective } \\
\text { study) }\end{array}$ & $\begin{array}{l}\text { Pooled analysis in } 540 \text { patients } \\
\text { treated with the combination of } \\
\text { CBZ/TIA }\end{array}$ & $\begin{array}{l}\text { Further evidence that a combination of CBZ/TIA is an } \\
\text { effective and safe treatment for alcohol withdrawal } \\
\text { treatment. }\end{array}$ \\
\hline Croissant et al. [38] & 2009 & $\begin{array}{l}\text { Randomized } \\
\text { clinical trial }\end{array}$ & $\begin{array}{l}\text { Comparison of the efficacy of the } \\
\text { combination of OXC/TIA and CLO }\end{array}$ & $\begin{array}{l}\text { There was no significant difference in safety, efficacy, and } \\
\text { tolerability between the combined treatment of OXC/TIA } \\
\text { and CLO. The combination of OXC/TIA is as safe as CLO in } \\
\text { an inpatient setting. }\end{array}$ \\
\hline Müller et al. [39] & 2011 & Case series & $\begin{array}{l}\text { Combination treatment of } \\
\text { Levetiracetam and TIA in } 9 \\
\text { alcohol-dependent patients in an } \\
\text { outpatient setting }\end{array}$ & $\begin{array}{l}\text { Combination of levetiracetam and TIA was a safe and } \\
\text { effective treatment option for mild to moderate withdrawal } \\
\text { symptoms in outpatient settings. }\end{array}$ \\
\hline Gartenmaier et al. [40] & 2005 & Case report & $\begin{array}{l}\text { Combination of CBZ/TIA in } \\
\text { treatment of alcohol withdrawal } \\
\text { symptoms in a patient with sleep } \\
\text { apnea syndrome }\end{array}$ & $\begin{array}{l}\text { This combination treatment was an effective alternative in } \\
\text { alcohol withdrawal without the risk of respiratory } \\
\text { depression. }\end{array}$ \\
\hline Lepola et al. [41] & 1984 & $\begin{array}{l}\text { Controlled } \\
\text { clinical trial }\end{array}$ & $\begin{array}{l}\text { Comparison of TIA vs. chlordiaz- } \\
\text { epoxide in acute alcohol } \\
\text { withdrawal }\end{array}$ & $\begin{array}{l}\text { Chlordiazepoxide was significantly more effective in } \\
\text { reducing the alcohol withdrawal symptoms in comparison } \\
\text { with TIA. }\end{array}$ \\
\hline Agricola et al. [42] & 1982 & $\begin{array}{l}\text { A double-blind } \\
\text { comparison } \\
\text { study }\end{array}$ & $\begin{array}{l}\text { The effect of CBZ vs. TIA in } \\
\text { treatment of acute alcohol } \\
\text { withdrawal syndrome }\end{array}$ & $\begin{array}{l}\text { Both drugs were equally effective in the treatment of } \\
\text { alcohol withdrawal symptoms. CBZ provided faster relief of } \\
\text { symptoms }\end{array}$ \\
\hline Dieh et al. [43] & 2007 & Case report & $\begin{array}{l}\text { Administration of a combined } \\
\text { CBZ and TIA in a } 45 \text {-year-old } \\
\text { alcohol-dependent patient }\end{array}$ & $\begin{array}{l}\text { The interaction between CBZ and TIA caused CBZ intoxica- } \\
\text { tion with serum levels up to } 19 \mathrm{mg} / \mathrm{L} \text {. This combination seem } \\
\text { not to be safe and should be used with cautious. }\end{array}$ \\
\hline
\end{tabular}

gradually reduced to a dosage between $100-300$ mg after 10 days. Both Franz et al. [35] and Lucht et al. [36] described a TIA/CBZ ratio of 1.5 as the optimal efficient dosage for this combination in inpatient setting. However, the dosage of CBZ used by Soyka et al. was $600 \mathrm{mg}$ in combination with $300 \mathrm{mg}$ TIA in outpatient individuals (TIA/CBZ ration of 0.5 ).

\section{CBZ in treatment of addiction to alcohol}

CBZ has been the most used medication administered as an adjunct therapy in combination with TIA. Not only can CBZ be used as prophylaxis for epileptic seizures, but it also can reinforce the alleviation of psychotic and vegetative symptoms of alcohol withdrawal when combined with TIA [35]. Various mechanisms of CBZ including inhibition of dopamine synthesis and modulation of glutaminergic, GABAergic, adrenergic, and cholinergic systems have been described so far [56, 57]. Mariani and Levin [58] mentioned in their study the necessity of alternatives to benzodiazepines for the pharmacological treatment of alcohol-related disorders particularly in outpatient setting. The favorable effect of CBZ in preventing withdrawal seizures and delirium tremens has been shown previously [59]. Seifert et al. [60] compared the efficacy of CBZ with clomethiazole in alcohol withdrawal. In this study CBZ was as effective as clomethiazole in reducing the initial withdrawal symptoms such as tremor, perspiration, and psychomotor agitation. Moreover, patients treated with CBZ showed significantly better verbal memory performance in comparison with clomethiazole [60]. Malcom et al. [61] compared the effect of lorazepam and CBZ in outpatient alcohol withdrawal and showed that both drugs were equally effective. However, CBZ is associated with lots of drug interactions, so other studies have recommended valproate as a better alternative to $C B Z$ regarding tolerability [62]. A 
Table 2 Sample size and outcome measures of the studies included in our meta-analysis.

\begin{tabular}{|c|c|c|c|c|c|c|}
\hline \multirow[t]{2}{*}{ Study } & \multicolumn{3}{|l|}{ TIA/CBZ group } & \multicolumn{3}{|c|}{ Comparison group (CLO or BZD) } \\
\hline & $\begin{array}{l}\text { CIWA-A mean } \pm \text { SD at the } \\
\text { beginning of the study }\end{array}$ & $\begin{array}{l}\text { CIWA-A mean } \pm \text { SD at } \\
\text { the end of the study }\end{array}$ & $\begin{array}{l}\text { Sample } \\
\text { size }\end{array}$ & $\begin{array}{l}\text { CIWA-A mean } \pm \text { SD at the } \\
\text { beginning of the study }\end{array}$ & $\begin{array}{l}\text { CIWA-A mean } \pm \text { SD at } \\
\text { the end of the study }\end{array}$ & $\begin{array}{l}\text { Sample } \\
\text { size }\end{array}$ \\
\hline Soyka et al. [26] 2002 & $18.29 \pm 4.2$ & $14.64 \pm 2.93$ & 50 & No comparison group & & \\
\hline Soyka et al. [24] 2006 & $12.3 \pm 8.3$ & $2.6 \pm 2.4$ & 540 & No comparison group & & \\
\hline Soyka et al. [27] 2006 & $5.0 \pm 4.1$ & $2.4 \pm 1.2$ & 116 & No comparison group & & \\
\hline Franz et al. [35] 2001 & $21.0 \pm 14.0$ & $1.0 \pm 3.2$ & 40 & $20.0 \pm 12.0$ & $1.5 \pm 4.0$ & 40 \\
\hline Lucht et al. [36] 2003 & \multicolumn{2}{|l|}{ Mean change: $0.29 \mathrm{~F}: 1,534$} & 26 & Mean change: $0.35 \mathrm{P}: 0.224$ & & 14 \\
\hline
\end{tabular}

- Table 3 The test of heterogeneity among the included studies as calculated by $\mathrm{X}^{2}$ test and $\mathrm{I}^{2}$ using Cochran heterogeneity statistic.

\begin{tabular}{|c|c|c|c|c|c|c|c|}
\hline \multirow[t]{2}{*}{ Model } & \multicolumn{2}{|c|}{ Test of null (2-tailed) } & \multirow{2}{*}{$\begin{array}{l}\text { Heterogeneity } \\
I^{2}\end{array}$} & \multicolumn{4}{|l|}{ Tau-squared } \\
\hline & z-value & p-value & & Tau-squared & Standard error & Variance & Tau \\
\hline Fixed & 27.21 & $<0.0001$ & 91.76 & 0.115 & 0.125 & 0.016 & 0.340 \\
\hline Random & 4.07 & $<0.0001$ & - & - & - & - & - \\
\hline
\end{tabular}

\begin{tabular}{|c|c|c|c|c|c|c|c|}
\hline \multirow[t]{2}{*}{$\underline{\text { Study name }}$} & \multicolumn{7}{|c|}{$\underline{\text { Statistics for each study }}$} \\
\hline & $\begin{array}{c}\text { Std diff } \\
\text { in means }\end{array}$ & $\begin{array}{l}\text { Standard } \\
\text { error }\end{array}$ & Variance & $\begin{array}{c}\text { Lower } \\
\text { limit }\end{array}$ & $\begin{array}{c}\text { Upper } \\
\text { limit }\end{array}$ & Z-Value & p-Value \\
\hline Franz et al. 2001 & 0.138 & 0.224 & 0.050 & -0.301 & 0.577 & 0.616 & 0.538 \\
\hline Soyka et al. 2002 & 0.943 & 0.132 & 0.017 & 0.685 & 1.201 & 7.160 & 0.000 \\
\hline Lucht et al. 2003 & 0.411 & 0.335 & 0.112 & -0.245 & 1.066 & 1.227 & 0.220 \\
\hline Soyka et al. $2006^{\mathrm{a}}$ & 1.099 & 0.042 & 0.002 & 1.016 & 1.181 & 26.030 & 0.000 \\
\hline Soyka et al. $2006^{\mathrm{b}}$ & 0.597 & 0.078 & 0.006 & 0.444 & 0.751 & 7.653 & 0.000 \\
\hline & 0.692 & 0.170 & 0.029 & 0.359 & 1.024 & 4.078 & 0.000 \\
\hline
\end{tabular}

$\underline{\text { Std diff in means and } 95 \% \mathrm{CI}}$

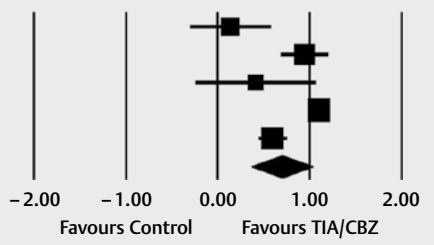

Fig. 1 Forest plot of the basic analysis using the random effect model. a reference number 24 , b reference number 27.

\begin{tabular}{|c|c|c|c|c|c|c|c|}
\hline \multirow[t]{2}{*}{$\underline{\text { Study name }}$} & \multicolumn{7}{|c|}{ Cumulative statistics } \\
\hline & Point & $\begin{array}{l}\text { Standard } \\
\text { error }\end{array}$ & Variance & $\begin{array}{l}\text { Lower } \\
\text { limit }\end{array}$ & $\begin{array}{l}\text { Upper } \\
\text { limit }\end{array}$ & Z-Value & 0 \\
\hline Franze & 0.138 & 0.224 & 0.050 & -0.301 & 0.577 & 0.616 & 0.538 \\
\hline Soyka et al. 2002 & 0.561 & 0.402 & 0.161 & -0.227 & 1.348 & 1.395 & 0.163 \\
\hline Lucht et al. 2003 & 0.526 & 0.290 & 0.084 & -0.043 & 1.094 & 1.813 & 0.070 \\
\hline Soyka et al. $2006^{\mathrm{a}}$ & 0.718 & 0.200 & 0.040 & 0.326 & 1.109 & 3.594 & 0.000 \\
\hline Soyka et al. $2006^{\mathrm{b}}$ & 0.692 & 0.170 & 0.029 & 0.359 & 1.024 & 4.078 & 0.000 \\
\hline & 0.692 & 0.170 & 0.029 & 0.359 & 1.024 & 4.078 & 0.000 \\
\hline
\end{tabular}

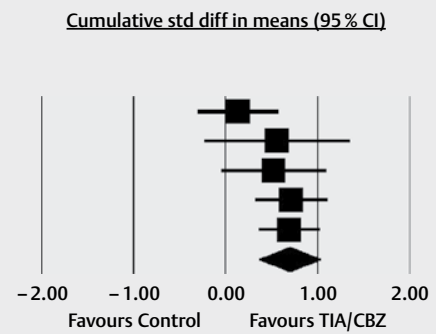

- Fig. 2 Forest plot of the cumulative analysis using the random effect model to illustrate the stability of outcomes through time. a reference number $24, \mathbf{b}$ reference number 27 .

literature review performed by Prince and Turpin [23] failed to approve the safety of CBZ application in alcohol withdrawal. However, the interaction between CBZ and alcohol remains still unclear. In this regard, Piekoszewski et al. [63] assessed the effect of ethanol on the pharmacokinetic and pharmacodynamic of CBZ in epileptic patients with alcohol dependence. Their study showed that ethanol does not influence the pharmacodynamic of CBZ in acute drug intoxication. Schick et al. [64] reported that both CBZ and OXC were similarly effective in stabilization of vegetative parameters and improvement in the cognitive processing speed. However, this study showed the beneficial effect of OXC in comparison with CBZ because of less drug interactions [64]. Nevertheless, studies have shown contradictory results regarding the usefulness of OXC in alcohol withdrawal. In this regard, Koethe et al. [65] found no significant difference in normalization of vegetative parameters, craving, or improvement of psychopathological parameters between OXC and placebo in treatment of AWS. Since OXC reduces the glutamatergic transmission at corticostriatal synapses, it has been supposed that this medication can have favorable effect in maintaining abstinence in patients with alcohol dependence. Croissant et al. [66] showed that the abstinence 


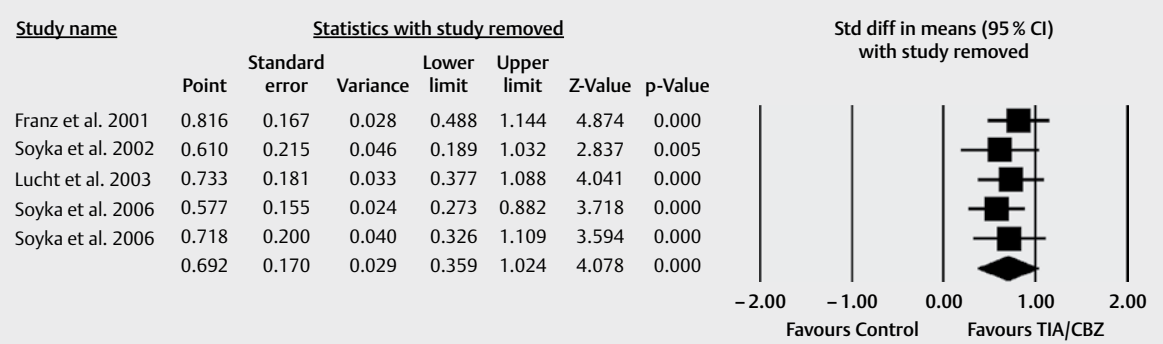

- Fig. 3 Leave-one-out study analysis as a component of sensitivity analysis showing that the findings were not driven by any single study.

duration was similar between patients treated with OXC and those treated with acamprosate. Furthermore, Martinotti et al. [67] demonstrated a favorable significant efficacy of high dosage of OXC (1500-1800 mg/day) in prevention of alcohol-relapse, whereas the lower dosage of OXC showed a weaker effectiveness that was comparable to naltrexone. Since OXC exerts mood stabilization effect, some studies have discussed that the favorable influence of OXC in preventing relapse in alcohol dependence is because of its positive effects on comorbid psychiatric disorders [67]. The mechanism of action of OXC is not yet fully understood. Some studies have also reported a dopaminergic effect if OXC which has caused rarely even psychotic symptoms [68]. However, OXC has been shown to be still a valuable alternative to benzodiazepines because of its better safety profile than classical anticonvulsant drugs and the absence of addictive properties $[69,70]$.

\section{Safety of the combination of TIA and CBZ in treatment of alcohol withdrawal symptoms}

Until now, studies have shown a good tolerability of this combination. However, some case reports have shown unwanted adverse effects of this treatment, so it should still be prescribed with caution. Diehl et al. [43] report a CBZ intoxication in a patient treated with the combination of CBZ and TIA. This result shows that the metabolism of CBZ could have been blocked or decelerated by TIA. There are still limited investigations addressing the interactions between TIA and other drugs. In this regard, Nozaki et al. [71] reported a case of neuroleptic malignant syndrome (NMS) induced by a combination therapy with tetrabenazine and TIA in a patient with Huntington's disease at the terminal stage of recurrent breast cancer. Another case of NMS in an alcoholic patient who received TIA has also been reported, which had led to patient's demise [72]. Furthermore, another study showed an induced Parkinsonism with a combination of TIA and donepezil since the cholinergic effect of donepezil combined with antidopaminergic effect of TIA had caused an acetylcholine/dopamine imbalance [73]. These reports show that the adverse effects of TIA, although rare, can cause life-threatening situations, although there are numerous studies that support the safety and effectiveness of this drug in management of alcohol dependence. In this field, Shaw et al. [74] reported that self-esteem and the subjective satisfaction with life can also be improved by TIA in alcoholic patients. The good tolerability of this medication and low risk of side effect have been reported frequently [74-77]. All these studies, inclusive our meta-analysis, prove that TIA can play an important role man- agement of alcoholism. However, its prescription should be initiated after the patients' informed consent.

\section{This study}

In our study, we reviewed the studies that had assessed the combination of TIA and CBZ as a possible alternative for benzodiazepines and clomethiazole. Our meta-analysis shows that this combination can reduce the withdrawal symptoms effectively $(p<0.0001)$. These results show that TIA and CBZ can effectively complete and intensify each other's influence in reducing AWS to treat vegetative symptoms as well as providing a good protection against epileptic attacks by increasing the seizure threshold. According to Franz et al. [35], the combination of TIA/CBZ could reduce the occurrence of seizures more effectively compared to clomethiazole. Moreover, the effect of TIA/CBZ has been reported to be faster than clomethiazole [35].

In our meta-analysis, we could not analyze or compare the dosages used in each study since we have evaluated the efficacy of the general prescribed treatment in comparison with a control group in that single study. Our analysis showed that the applied treatment with the mentioned dosage exerts a significant effect in reducing AWS. However, it seems that the less severe vegetative symptoms in outpatient cases lead to lower required dosage of TIA, whereby the CBZ dosage seems to be similar between inpatient and outpatient settings.

Our meta-analysis was only able to approve the efficacy of combination of TIA/CBZ as an appropriate treatment option, whereas the safety of its administration still has to be proven by further investigation.

\section{Conclusion}

Our study shows that the combination of TIA/CBZ is an effective treatment in management of AWS in patients with alcohol abstinence. However, the safety of this combination could not be proved, so we recommend its prescription after an informed consent. In cases of intolerance, $O X C$ is a valuable alternative to $C B Z$, which can be taken into consideration.

\section{Conflicts of Interest}

Prof. Dr. Thomas Messer received honoraria from Janssen-Cilag, Ferrer, Otsuka/Lundbeck and Bayer Vital. Dr. Sahar Latifi declares no conflicts of interest. 


\section{References}

[1] Addolorato G, Leggio L, Abenavoli L et al. Neurobiochemical and clinical aspects of craving in alcohol addiction: A review. Addict Behav 2005; 30: 1209-1224

[2] Littleton J. Neurochemical mechanisms underlying alcohol withdrawal. Alcohol Health ResWorld 1998; 22: 13-24

[3] Glue P, Nutt D. Overexcitement and disinhibition. Dynamic neurotransmitter interactions in alcohol withdrawal. Br J Psychiat 1990; 157 : 491-499

[4] Swift RM. Drug therapy for alcohol dependence. N Engl J Med 1999; 340: 1482-1490

[5] Koob GF. A role for GABA mechanisms in the motivational effects of alcohol. Biochem Pharmacol 2004; 68: 1515-1525

[6] Stojakovic A, Walczak M, Cieślak PE et al. Several behavioral traits relevant for alcoholism are controlled by $\gamma 2$ subunit containing GABAA receptors on dopamine neurons in mice. Neuropsychopharmacology 2018; 43: 1548-1556

[7] Laine TP, Ahonen A, Torniainen P et al. Dopamine transporters increase in human brain after alcohol withdrawal. Mol Psychiatry 1999; 4: 189-191

[8] De Witte P, Pinto E, Ansseau $\mathrm{M}$ et al. Alcohol and withdrawal: From animal research to clinical issues. Neurosci Biobehav Rev 2003; 27 : 189-197

[9] Bonnet U, Lensing M, Specka M et al. Comparison of two oral symptom-triggered pharmacological inpatient treatments of acute alcohol withdrawal: clomethiazole vs. clonazepam. Alcohol Alcohol 2011; 46: 68-73

[10] Sychla H, Gründer G, Lammertz SE. Comparison of clomethiazole and diazepam in the treatment of alcohol withdrawal syndrome in clinical practice. Eur Addict Res 2017; 23: 211-218

[11] Mayo-Smith MF. Pharmacologicalmanagement of alcohol withdrawal: A meta-analysis and evidence-based practice guideline: American Society of Addiction Medicine Working Group on Pharmacological Management of Alcohol Withdrawal. JAMA 1997; 278: 144-151

[12] Verthein U, Kuhn S, Gabriel K et al. Treatment of alcohol withdrawal syndrome with oxazepam or clomethiazole - A naturalistic observational study. Psychiatr Prax 2018; 45: 95-102

[13] Williams D, McBride AJ. The drug treatment of alcohol withdrawal symptoms: A systematic review. Alcohol Alcohol 1998; 33: 103-115

[14] Simona G, Lanfranco P, Alberto PL et al. Drug-drug interactions in the treatment for alcohol use disorders: A comprehensive review. Pharmacol Res 2018; 133: 65-76

[15] Maldonado JR. Novel algorithms for the prophylaxis and management of alcohol withdrawal syndromes-beyond benzodiazepines. Crit Care Clin 2017; 33: 559-599

[16] Ross HE. Benzodiazepine use and anxiolytic abuse and dependence in treated alcoholics. Addiction 1993; 88: 209-218

[17] Khong E, Sim MG, Hulse G. Benzodiazepine dependence. Aust Fam Physician 2004; 33: 923-926

[18] Kattimani S, Bharadwaj B, Arun AB. Benzodiazepine maintenance for alcohol dependence: A case series. J Family Med Prim Care 2017; 6: 431-433

[19] Leggio L, Kenna GA, Swift RM. New developments for the pharmacological treatment of alcohol withdrawal syndrome. A focus on non-benzodiazepine GABAergic medications. Prog Neuropsychopharmacol Biol Psychiatry 2008; 32: 1106-1117

[20] Barrons R, Roberts N. The role of carbamazepine and oxcarbazepine in alcohol withdrawal syndrome. J Clin Pharm Ther 2010; 35: 153-167

[21] Minozzi S, Amato L, Vecchi S et al. Anticonvulsants for alcohol withdrawal. Cochrane Database Syst Rev 2010; 3: CD005064

[22] Bonnet U, Schäfer M, Richter C et al. Anticonvulsants in the treatment of alcoholism. Fortschr Neurol Psychiatr 2009; 77: 192-202
[23] Prince V, Turpin KR. Treatment of alcohol withdrawal syndrome with carbamazepine, gabapentin, and nitrous oxide. Am J Health Syst Pharm 2008; 65: 1039-1047

[24] Scatton B, Cohen C, Perrault G et al. The preclinical pharmacologic profile of tiapride. Eur Psychiatry 2001; 16: (Suppl 1): 29s-34s

[25] Soyka M, Schmidt P, Franz M et al. Treatment of alcohol withdrawal syndrome with a combination of tiapride/carbamazepine: Results of a pooled analysis in 540 patients. Eur Arch Psychiatry Clin Neurosci 2006; 256: 395-401

[26] Soyka M, Morhart-Klute V, Horak M. A combination of carbamazepine/ tiapride in outpatient alcohol detoxification. Results from an open clinical study. Eur Arch Psychiatry Clin Neurosci 2002; 252: 197-200

[27] Soyka M, Schmidt F, Schmidt P. Efficacy and safety of outpatient alcohol detoxification with a combination of tiapride/carbamazepine: Additional evidence. Pharmacopsychiatry 2006; 39: 30-34

[28] Russell ], Richardson N, Dar A. Use of a modified Clinical Institute Withdrawal Assessment (CIWA) for symptom-triggered management of alcohol withdrawal syndrome. Clin Med (Lond) 2015; 15: (Suppl 3): s20

[29] Bakhla AK, Khess CR, Verma V et al. Factor structure of CIWA-Ar in alcohol withdrawal. J Addict 2014; 2014; 745839

[30] Higgins JP, Thompson SG, Deeks J] et al. Measuring inconsistency in meta-analyses. BM] 2003; 327: 557-560

[31] Koushki D, Latifi S, Norouzi Javidan A et al. Efficacy of some nonconventional herbal medications (sulforaphane, tanshinone IIA, and tetramethylpyrazine) in inducing neuroprotection in comparison with interleukin-10 after spinal cord injury: A meta-analysis. J. Spinal Cord Med 2015; 38: 13-22

[32] Kontopantelis E, Springate DA, Reeves D. A re-analysis of the Cochrane Library data: The dangers of unobserved heterogeneity in meta-analyses. PLoS One 2013; 8: e69930

[33] Messer T, Lammers G, Müller-Siecheneder F et al. Substance abuse in patients with bipolar disorder: A systematic review and meta-analysis. Psychiatry Res 2017; 253: 338-350

[34] Rosenthal R. The "file drawer problem" and tolerance for null results. Psychol Bull 1979; 86: 638-641

[35] Franz M, Dlabal H, Kunz S et al. Treatment of alcohol withdrawal: Tiapride and carbamazepine versus clomethiazole. A pilot study. Eur Arch Psychiatry Clin Neurosci 2001; 251: 185-192

[36] Lucht M, Kuehn KU, Armbruster ] et al. Alcohol withdrawal treatment in intoxicated vs non-intoxicated patients: A controlled open-label study with tiapride/carbamazepine, clomethiazole and diazepam. Alcohol Alcohol 2003; 38: 168-175

[37] Martinotti G, di Nicola M, Frustaci A et al. Pregabalin, tiapride and lorazepam in alcohol withdrawal syndrome: A multi-centre, randomized, single-blind comparison trial. Addiction 2010; 105: 288-299

[38] Croissant B, Loeber S, Diehl A et al. Oxcarbazepine in combination with Tiaprid in inpatient alcohol-withdrawal-a RCT. Pharmacopsychiatry 2009; 42: 175-181

[39] Müller CA, Schäfer M, Banas R et al. A combination of levetiracetam and tiapride for outpatient alcohol detoxification: A case series. J Addict Med 2011; 5: 153-156

[40] Gartenmaier A, Pelzer E, Soyka M. Treatment of alcohol withdrawal syndrome with combined carbamazepine and tiapride in a patient with probable sleep apnoe syndrome. Pharmacopsychiatry 2005; 38 : 96-98

[41] Lepola U, Kokko S, Nuutila J et al. Tiapride and chlordiazepoxide in acute alcohol withdrawal. A controlled clinical trial. Int J Clin Pharmacol Res 1984; 4: 321-326

[42] Agricola R, Mazzarino M, Urani R et al. Treatment of acute alcoho withdrawal syndrome with carbamazepine: A double-blind comparison with tiapride. J Int Med Res 1982; 10: 160-165 
[43] Diehl A, Grosshans M, Herre $\mathrm{H}$ et al. Carbamazepine intoxication. Complication of alcohol detoxification with combined carbamazepine and tiapride. Nervenarzt 2007; 78: 85-89

[44] Sullivan JT, Sykora K, Schneiderman J et al. Assessment of alcohol withdrawal: The revised clinical institute withdrawal assessment for alcohol scale (CIWA-Ar). Br J Addict 1989; 84: 1353-1357

[45] Eloma AS, Tucciarone JM, Hayes EM et al. Evaluation of the appropriate use of a CIWA-Ar alcohol withdrawal protocol in the general hospital setting. Am J Drug Alcohol Abuse 2018; 44: 418-425

[46] Pittman B, Gueorguieva R, Krupitsky E et al. Multidimensionality of the Alcohol Withdrawal Symptom Checklist: a factor analysis of the Alcohol Withdrawal Symptom Checklist and CIWA-Ar. Alcohol Clin Exp Res 2007; 31: 612-618

[47] Shaw GK, Waller S, Majumdar SK et al. Tiapride in the prevention of relapse in recently detoxified alcoholics. Br J Psychiatry 1994; 165: 515-523

[48] Bender S, Scherbaum N, Soyka M et al. The efficacy of the dopamine D2/D3 antagonist tiapride in maintaining abstinence: A randomized, double-blind, placebo-controlled trial in 299 alcohol-dependent patients. Int J Neuropsychopharmacol 2007; 10: 653-660

[49] Peters DH, Faulds D. Tiapride. A review of its pharmacology and therapeutic potential in the management of alcohol dependence syndrome. Drugs 1994; 47: 1010-1032

[50] Murphy D], Shaw GK, Clarke L. Tiapride and chlormethiazole in alcohol withdrawal: a double-blind trial. Alcohol and Alcoholism 1983; 18 : 227-237

[51] Cazzato G, Gioseffi M, Torre P et al. Prevention and therapy of delirium tremens with tiapride. Riv Neurol 1982; 52: 379-391

[52] Léger JM, Herrmann C, Danot G et al. Double-blind comparative study of lorazepam and tiapride effects on the memory capacities of subjects over 60 years of age. Sem Hop 1984; 60: 932-936

[53] Dose M, Lange HW. The benzamide tiapride: treatment of extrapyramidal motor and other clinical syndromes. Pharmacopsychiatry 2000; 33: 19-27

[54] Robert PH, Allain H. Clinical management of agitation in the elderly with tiapride. Eur Psychiatry 2001; 16: (Suppl 1): 42s-47s

[55] Yuan Y, Li LH, Huang Y] et al. Tiapride is more effective and causes fewer adverse effects than risperidone in the treatment of senile dementia. Eur Rev Med Pharmacol Sci 2016; 20: 3119-3122

[56] Thome J, Wiesbeck GA, Vince GH. Carbamazepine in treatment of alcohol withdrawal syndrome-an overview of current research. Fortschr Neurol Psychiatr 1994; 62: 125-133

[57] Rybakowski ], Wankiewicz G. Mechanism of the psychotropic action of carbamazepine. Psychiatr Pol 1989; 23: 314-321

[58] Mariani ]J, Levin FR. Pharmacotherapy for alcohol-related disorders: What clinicians should know. Harv Rev Psychiat 2004; 23: 351-366

[59] See S. Carbamazepine effective for alcohol withdrawal. J Fam Pract 2002; $51: 778$

[60] Seifert J, Peters E, Jahn K et al. Treatment of alcohol withdrawal: Chlormethiazole vs. carbamazepine and the effect on memory performance-a pilot study. Addict Biol 2004; 9: 43-51
[61] Malcolm R, Myrick H, Roberts ] et al. The effects of carbamazepine and lorazepam on single versus multiple previous alcohol withdrawals in an outpatient randomized trial. J Gen Intern Med 2002; 17: 349-355

[62] Eyer F, Schreckenberg M, Hecht D et al. Carbamazepine and valproate as adjuncts in the treatment of alcohol withdrawal syndrome: $\mathrm{A}$ retrospective cohort study. Alcohol Alcohol 2011; 46: 177-184

[63] Piekoszewski W, Florek E, Szpak D et al. Carbamazepine intoxication in alcohol dependent epileptic patients. Pharmacol Rep 2010; 62: 398-404

[64] Schik G, Wedegaertner FR, Liersch J et al. Oxcarbazepine versus carbamazepine in the treatment of alcohol withdrawal. Addict Biol 2005; 10: 283-288

[65] Koethe D, Juelicher A, Nolden BM et al. Oxcarbazepine-efficacy and tolerability during treatment of alcohol withdrawal: A double-blind, randomized, placebo-controlled multicenter pilot study. Alcohol Clin Exp Res 2007; 31: 1188-1194

[66] Croissant B, Diehl A, Klein O et al. A pilot study of oxcarbazepine versus acamprosate in alcohol-dependent patients. Alcohol Clin Exp Res 2006; 30: 630-635

[67] Martinotti G, Di Nicola M, Romanelli R et al. High and low dosage oxcarbazepine versus naltrexone for the prevention of relapse in alcohol-dependent patients. Hum Psychopharmacol 2007; 22: 149-156

[68] Kovacs N, Nagy F, Balas I et al. Oxcarbazepine may induce psychotic symptoms in Parkinson's disease. Epilepsy Behav 2008; 12: 492-493

[69] Ponce G, Rodríguez-jiménez R, Ortiz $\mathrm{H}$ et al. Oxcarbazepine in the prevention of epileptic syndromes in alcohol detoxification. Rev Neurol 2005; 40: 577-580

[70] Lu BY, Coberly R, Bogenschutz M. Use of oxcarbazepine in outpatient alcohol detoxification. Am J Addict 2005; 14: 191-192

[71] Nozaki I, Furukawa Y, Kato-Motozaki Y et al. Neuroleptic malignant syndrome induced by combination therapy with tetrabenazine and tiapride in a Japanese patient with Huntington's disease at the terminal stage of recurrent breast cancer. Intern Med 2014; 53: 1201-1204

[72] Tamion F, Petit J, Massari P et al. Malignant Neuroleptic Syndrome during tiapride treatment. J Toxicol Clin Exp 1990; 10: 461-467

[73] Arai M. Parkinsonism onset in a patient concurrently using tiapride and donepezil. Intern Med 2000; 39: 863

[74] Shaw GK, Majumdar SK, Waller S et al. Tiapride in the long-term management of alcoholics of anxious or depressive temperament. $\mathrm{Br}$ J Psychiatry 1987; 150: 164-168

[75] Vandel B, Bonin B, Vandel S et al. Interaction between tiapride and alcohol in man. Sem Hop. 1984; 60: 175-177

[76] Chaillou E, Perré P. The weaning of alcoholic patients in a general medicine hospital department. The value of tiapride. Sem Hop 1983; 59: $1677-1678$

[77] Stecchini M, Corrias G. Treatment of alcoholic patients with tiapride. Sem Hop 1982; 58: 2724-2726 